\title{
Rintisan Desa Tangguh Bencana (Destana) Di Desa Gitgit, Kecamatan Sukasada, Kabupaten Buleleng
}

\author{
I Wayan Krisna Eka Putra ${ }^{1 *}$, I Putu Gede Diatmika² \\ ${ }_{1}^{1}$ Jurusan D3 Survei dan Pemetaan, Universitas Pendidikan Ganesha, Singaraja, Indonesia \\ 2 Jurusan D3 Akuntansi, Universitas Pendidikan Ganesha, Singaraja, Indonesia
}

\section{A R T I C L E I N F O}

Article history:

Received 31 Oktober 2018

Accepted 30 November 2018

Available online 31

Desember 2018

Kata Kunci:

Bencana; Tanah longsor;

Destana

Keywords:

Disaster; Landslide;

Desatana

\begin{abstract}
A B S T R A K
Kejadian bencana tanah longsor di daerah yang menjadi arteri transportasi Bali Utara dengan Bali Selatan yaitu Desa Gitgit seakan menjadi fenomena siklus tahunan dengan risiko dampak yang cenderung lebih tinggi, sehingga memaksa pemerintah harus segera melakukan upaya pengurangan risiko bencana. Salah satu kegiatan yang dilakukan adalah merintis Desa Gitgit menjadi Destana, yaitu suatu kegiatan yang ditujukan untuk sebuah desa atau kelurahan agar mampu mengenali ancaman di wilayahnya dan mampu mengorganisir sumber daya masyarakat untuk mengurangi kerentanan dan sekaligus meningkatkan kapasitas demi mengurangi risiko bencana. Melalui program destana, setidaknya risiko bencana yang sering terjadi di Desa Gitgit dapat diminimalisir, jika bisa dikendalikan 2 indikator risiko bencana yaitu: menurunkan indeks kerentanan dan meningkatkan kapasitas bencana. Guna merintis program Desa Gitgit Tangguh bencana, pihak yang terlibat
\end{abstract} adalah tim relawan Desa Gitgit, para Kepala Dusun beserta kelompok suka-duka di Desa Gitgit yang difasilitasi oleh BPBD Kabupaten Buleleng. Tahapan awal dalam merintis desa tangguh bencana yang dilakukan dalam kegiatan ini yaitu : (1) pengkajian risiko bencana dan (2) pembentukan forum PRB Desa. Hasil yang diperoleh dari kegiatan ini adalah tersedianya berbagai indikator desa tangguh bencana yang meliputi perencanaan, kelembagaan, pengembangan kapasitas, dan penyelenggaraan penanggulangan bencana.

\begin{abstract}
A B S T R A C T
Landslides in the area that become the transportation arteries of North Bali with South Bali, namely Gitgit Village, seem to be a phenomenon of the annual cycle with a higher risk of impact, thus forcing the government to immediately undertake disaster risk reduction efforts. One of the activities carried out was pioneering Gitgit Village to Destana, an activity aimed at a village or kelurahan to be able to recognize threats in their area and be able to organize community resources to reduce vulnerability and simultaneously increase capacity to reduce disaster risk. Through the destana program, at least the disaster risk that often occurs in Gitgit Village can be minimized, if it can be controlled by 2 disaster risk indicators, namely: reducing the vulnerability index and increasing disaster capacity. In order to pioneer the Gitgit Tangguh Village program, the parties involved were the volunteer team of Gitgit Village, Village Heads and grief groups in Gitgit Village facilitated by BPBD of Buleleng Regency. The initial stages in pioneering resilient villages carried out in this activity were: (1) disaster risk assessment and (2) establishment of Village DRR forums. The results obtained from this activity were the availability of various resilient village indicators which included planning, institutions, capacity building, and the implementation of disaster management.
\end{abstract}

\footnotetext{
* Corresponding author.

E-mail addresses: krisna.ekaputra@yahoo.com
} 


\section{Pendahuluan}

Buleleng merupakan salah satu kabupaten di Provinsi Bali yang secara geografis terletak pada 08o03'40"- 08o23'00" LS dan 114o25'55"-115o27'28" BT (BPS Kabupaten Buleleng, 2012). Potensi bencana Kabupaten Buleleng yang divisualisasikan melalui peta rawan bencana terdiri dari bencana banjir, longsor, dan gempa. Sebaran potensi bencana tersebut tergantung dari karakteristik wilayahnya. Biasanya banjir berpotensi di daerah dataran rendah, longsor berpotensi di daerah dataran tinggi, sementara gempa berpotensi di daerah yang dilalui patahan.

Berdasarkan pengamatan lapangan, bencana yang sering terjadi khususnya di daerah dataran tinggi Buleleng sebagian besar berpotensi longsor. Tanpa adanya upaya mitigasi bencana sering kali bencana tersebut akan memiliki dampak negatif yang cukup besar bagi kelangsungan kehidupan masyarakat daerah tersebut. Sebagai contoh kejadian bencana longsor yang pernah terjadi daerah dataran tinggi sepanjang jalur Singaraja-Bedugul berdampak langsung pada kelancaran arus transportasi yang melewati jalur tersebut. Dengan demikian peningkatan kapasitas masyarakat melalui program desa tangguh bencana di Desa Gitgit merupakan program yang urgen untuk dilakukan. Program desa tangguh bencana ditujukan agar desa yang berpotensi bencana memiliki kemampuan mandiri untuk beradaptasi dan menghadapi ancaman bencana, serta memulihkan diri dengan segera dari dampak bencana yang merugikan. Program desa tangguh bencana merupakan bagian dari pengembangan kapasitas masyarakat terhadap bencana yang mungkin terjadi (BNPB, 2015).

Berdasarkan informasi dari kepala Desa Gitgit bahwa Desa Gitgit sendiri sangat berpotensi terjadi bencana longsor. Guna mengantisipasi hal tersebut, merintis progam Desa Gitgit Tangguh bencana merupakan suatu keniscayaan agar mampu meminimalisir dampak risiko bencana yang ditimbulkan. Kajian mengenai program destana sudah cukup banyak diungkap oleh para peneliti, diantaranya: Munir (2017) tentang evaluasi pelaksanaan program destana, sementara Nora (2017) mengenai partisipasi masyarakat tentang destana. Senada dengan penelitian yang sudah dilakukan tersebut, dalam penelitian ini lebih dititikberatkan pada membangun komitmen bersama bahwa penanganan bencana merupakan tanggung jawab seluruh komponen tidak hanya pemerintah, melainkan juga masyarakat dan dunia usaha. Hal ini sejalan dengan prinsip penanggulangan bencana sesuai dengan UU No 24 tahun 2007.

\section{Metode}

Metode yang digunakan dalam kegiatan ini adalah metode pendekatan pemberdayaan dengan prinsip partisipasi dari staff BPBD dan masyarakat Desa Gitgit. Metode pelaksanaan program ini dilakukan melalui beberapa tahapan yaitu: (1) pengkajian risiko bencana Desa Gitgit, dan (2) pembentukan forum PRB Desa. Pada akhirnya diharapkan masyarakat Desa Gitgit memiliki rambu-rambu yang jelas tentang PRB yang selanjutnya dapat digunakan sebagai landasan program untuk diusulkan masuk ke dalam rencana anggaran desa. Keberlanjutan jangka panjang ketika terjadi bencana masyarakat sudah siap siaga menghadapi bencana. Disamping itu forum PRB yang dibuat sigap dalam menghadapi bencana, serta terjalin komunikasi dengan BPBD.

\section{Hasil dan pembahasan}

\subsection{Pengkajian Risiko Bencana Desa Gitgit}

Pendefinisian risiko bencana di suatu daerah, tidak terlepas dari variabel utama yang menentukan risiko, atau dengan kata lain risiko merupakan fungsi dari ancaman, kerentanan, dan kapasitas.

$\mathrm{R}=\mathrm{f}(\mathrm{A}, \mathrm{Ke}, \mathrm{Ka})$

$\mathrm{R}=$ Risiko Bencana

$\mathrm{A}=$ Ancaman Bencana

Ke $=$ Kerentanan Bencana

$\mathrm{Ka}=$ Kapasitas Bencana 
Risiko bencana merupakan potensi kerugian yang ditimbulkan pasca bencana pada suatu wilayah. Pengkajian risiko bencana merupakan sebuah pendekatan untuk memperlihatkan potensi dampak negatif yang mungkin timbul akibat suatu potensi bencana yang melanda. Potensi risiko yang mungkin terjadi mempertimbangkan tingkat kerentanan dan kapasitas wilayah terhadap bencana. Upaya mengetahui risiko dan kerentanan merupakan komponen penting dalam upaya mitigasi bencana guna mengurangi risiko suatu bencana (UU RI. No. 24 Tahun 2007).

Kajian risiko bencana merupakan suatu upaya yang dapat dilakukan untuk menilai kecenderungan dan besarnya kerugian akibat ancaman yang ada, sehingga fokus utama perencanaan dan penyelenggaraan penanggulangan bencana menjadi lebih efektif. Kajian risiko bencana juga mengandung makna sebagai suatu upaya untuk menjamin keselarasan arah dan efektivitas realisasi penanggulangan bencana pada suatu daerah. Mekanisme pengkajian risiko bencana menurut Peraturan Kepala BNPB No. 2 Tahun 2012, dapat melalui peta risiko bencana yang metode penyusunannya disajikan melalui Gambar 1.

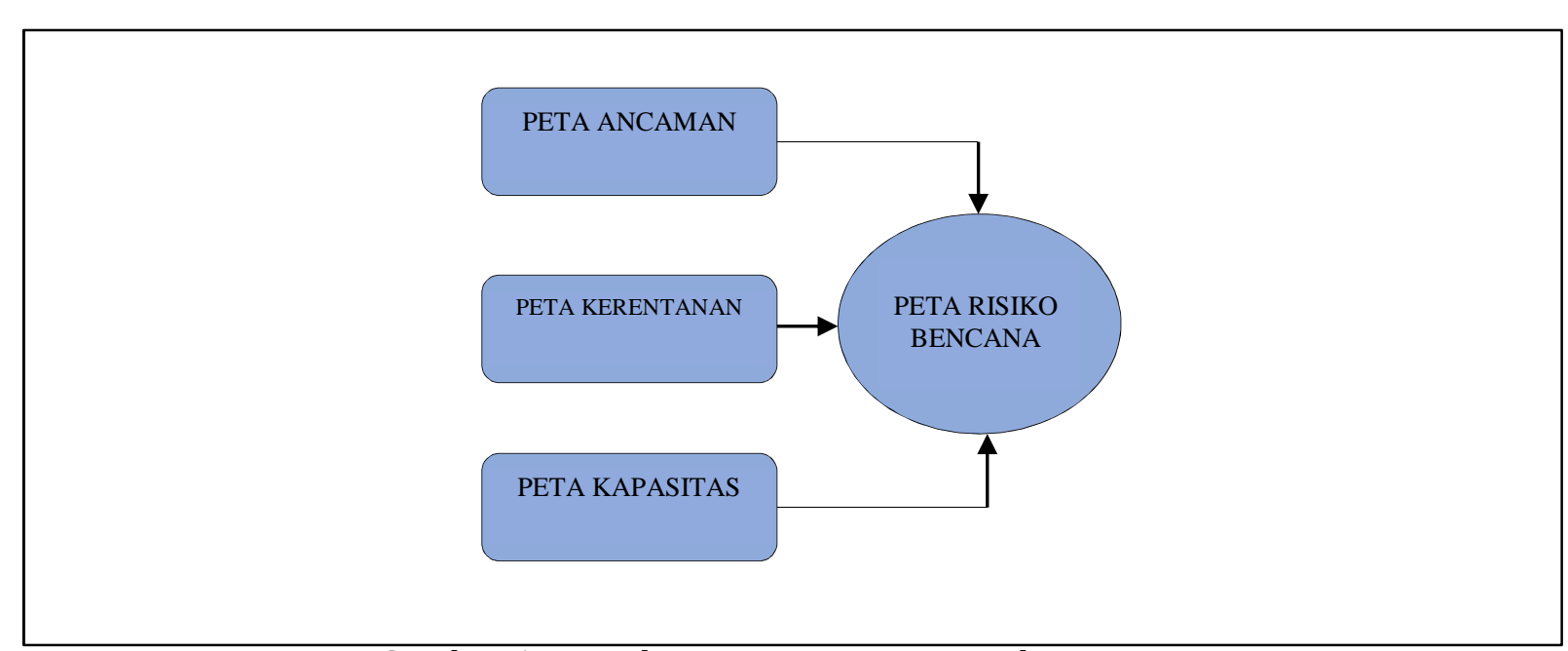

Gambar 1. Metode Penyusunan Peta Risiko Bencana

Sumber: Peraturan Kepala BNPB No. 2 Tahun 2012

Sesuai dengan Gambar 1, lebih jelasnya mengenai kajian risiko bencana dapat dirumuskan dengan menggunakan pendekatan sebagai berikut (Peraturan Kepala BNPB No. 2 Tahun 2012).

$$
R \quad \approx A 1 \quad * \frac{K}{K}
$$

Perlu menjadi catatan bahwa pendekatan yang digunakan untuk mendefinisikan risiko bencana tersebut tidak dapat disamakan dengan rumus matematika. Pendekatan tersebut hanya menyajikan hubungan antara ancaman, kerentanan dan kapasitas yang mendefinisikan pespektif tingkat risiko bencana pada suatu wilayah. Agar lebih memudahkan dalam melakukan analisis maka dijabarkan menjadi Gambar 2.
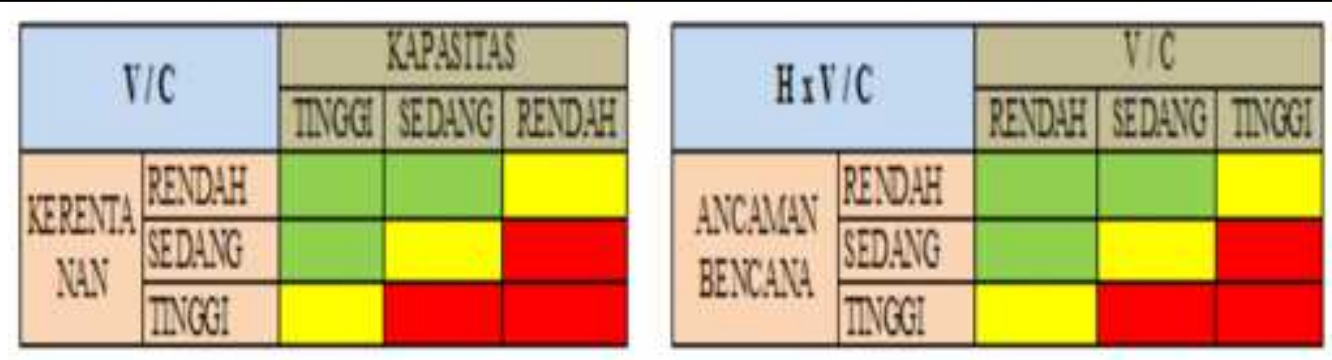

Gambar 2. Pedoman Menentukan Tingkat Risiko Bencana 
Berdasarkan kegiatan yang sudah dilakukan, maka peta risiko bencana di Desa Gitgit disajikan seperti terlihat pada Gambar 3.

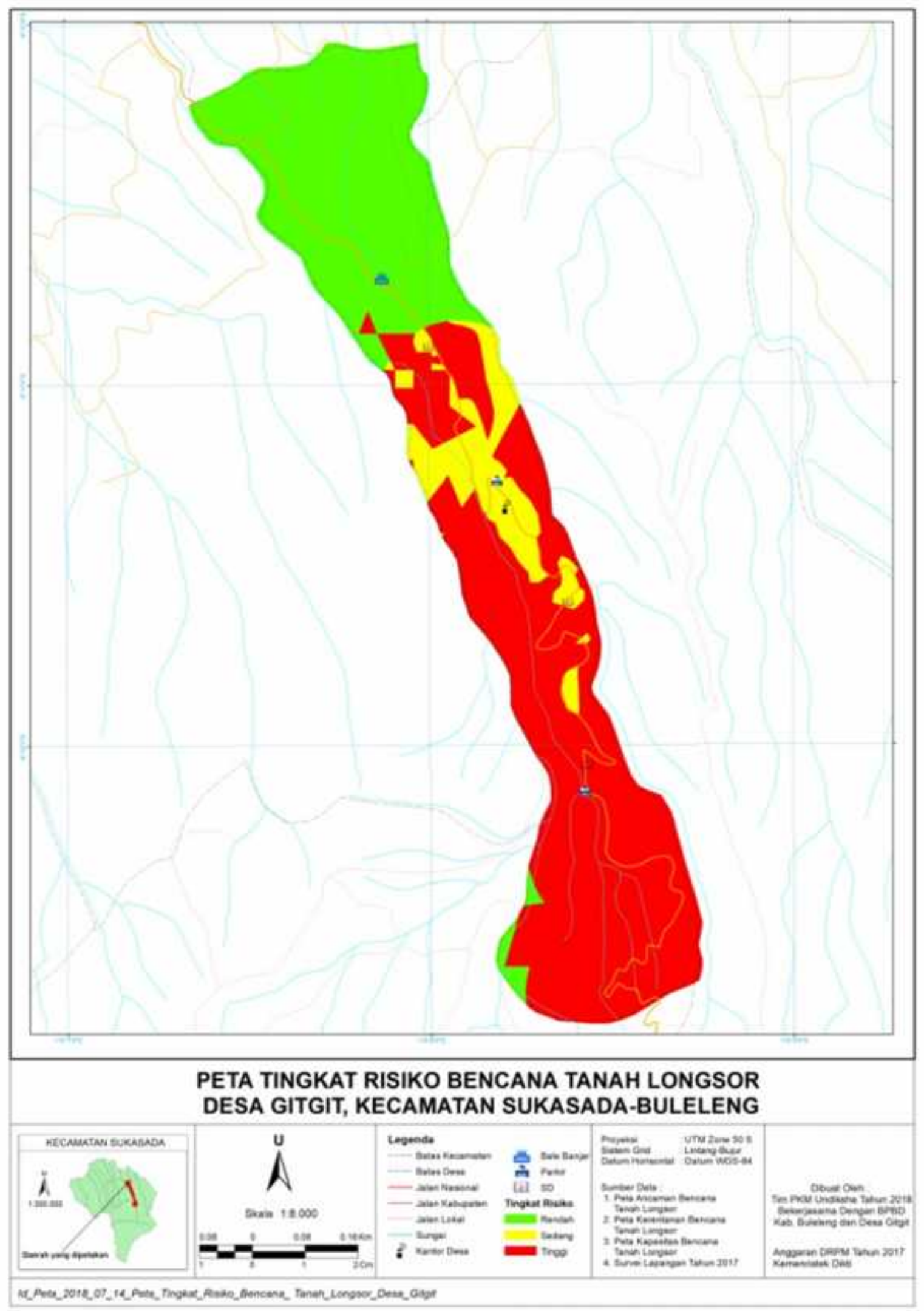

Gambar 3. Peta Risiko Bencana Tanah Longsor Desa Gitgit 
Memperhatikan 3, sepanjang jalur transportasi yang ada di wilayah Desa Gitgit mulai dari 8o10'51"LS, 115o7'59"BT sampai 8011'37"LS, 115o8'23"BT memiliki potensi sedang, sementara 8o11'37"LS, 115o8'23"BT sampai 8o12'42"LS, 115o8'38"BT memiliki potensi tinggi. Berdasarkan uji sampel secara purposive sampling terhadap 10 titik sampel yang dilakukan oleh Putra (2017), diperoleh 5 titik sampel sudah mengalami longsor dan 5 titik sampel belum mengalami longsor. Sampel yang kondisi eksistingnya sudah mengalami longsor terjadi pada daerah yang berpotensi sedang-tinggi, sementara sampel yang belum mengalami longsor terjadi pada daerah yang berpotensi rendah. Kondisi eksisting di lapangan ini menguatkan bahwa rintisan program destana di Desa Gitgit sangat penting untuk segera direalisasikan. Melalui program Desa Tangguh Bencana, setidaknya kejadian bencana tanah longsor yang sering terjadi di Desa Gitgit tidak membawa dampak risiko tinggi, jika bisa dikendalikan 2 indikator risiko bencana yaitu: menurunkan indeks kerentanan dan meningkatkan kapasitas bencana. Hal ini bermakna bahwa program Desa Tanguh Bencana cukup handal dalam meminimalisir dampak dari risiko bencana. Dalam merintis program Desa Gitgit Tangguh bencana melibatkan aparat desa dan BPBD, termasuk sumbangsih pemikiran dari akedemisi/praktisi di bidang yang relevan.

\subsection{Pembentukan Forum PRB Desa}

Berdasarkan hasil kegiatan sosialisasi awal yang dilakukan, bahwa pihak Desa Gitgit dan BPBD Kabupaten Buleleng berkomitmen mendukung program merintis Desa Gitgit sebagai Desa Tangguh Bencana. Forum PRB Desa merupakan kelompok yang dibentuk untuk mampu berkoordinasi dalam mendukung program Desa Tangguh Bencana. Forum PRB Desa Gitgit yang dibentuk merupakan hasil kesepakatan dari semua peserta yang ikut dalam pelatihan. Sebagai komitmen awal dari forum ini adalah dengan dibentuknya group komunikasi (Group Whatshap) dengan nama Destana Gitgit. Gambar 4 merupakan visualisasi group PRB yang sudah dibuat.

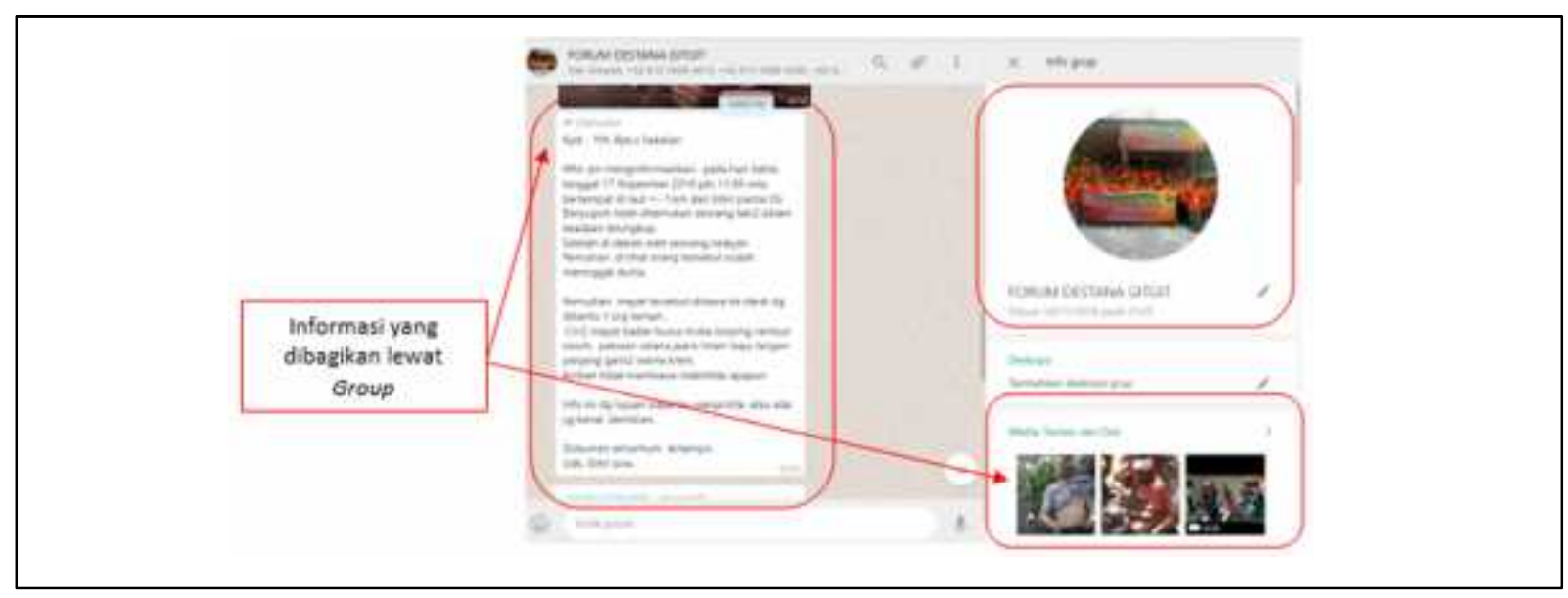

Gambar 4. Group Komunikasi Forum PRB Desa Gitgit

Berbagai informasi terkait dengan kebencanaan yang terjadi khususnya di Desa Gitgit dikomunikasikan melalui group tersebut, sehingga harapannya semua pihak mengetahui informasi yang valid tentang kejadian bencana yang terjadi di Desa Gitgit. Kemudian seijin Kepala Desa Gitgit, maka forum yang terbentuk dari kegiatan ini dibuatkan SK Tim Forum PRB Desa Gitgit sebagaimana. Kedepannya diharapkan melalui adanya SK Tim PRB ini, pihak desa mampu mengalokasikan anggaran desa untuk kegiatan penguatan kapasitas bagi anggota Forum PRB. Pada akhirnya, pelaksanaan program Desa Tangguh Bencana di Desa Gitgit ini mampu ajeg tidak hanya kebijakannya melainkan juga pengetahuan tim yang tergabung dalam forum PRB 


\section{Simpulan dan saran}

Kegiatan dalam rangka merintis Desa Gitgit menjadi desa tangguh bencana sudah terlaksana sampai pada tahap penetapan perencanaan penanggulangan bencana dan penetapan forum PRB, penetapan peta risiko bencana. Peserta dalam hal ini tim relawan sangat antusias mengikuti kegiatan yang sudah dilakukan. Produk yang dihasilkan dari kegiatan ini adalah tersedianya peta risiko bencana dan SK forum PRB. Selain produk fisik tersebut, hasil yang diperoleh dari kegiatan ini adalah berupa pemahaman masyarakat utamanya tim relawan sebagai pelaku penanggulangan bencana tentang upaya-upaya penanggulangan bencana.

\section{Daftar Rujukan}

BNPB. 2012, Pedoman Umum Pengkajian Risiko Bencana. Peraturan Kepala Badan Nasional Penanggulangan Bencana No. 2 Tahun 2012.

BNPB. 2012. Pedoman Desa/Kelurahan Tangguh Bencana. Peraturan Kepala Badan Nasional Penanggulangan Bencana No.1 Tahun 2012.

BNPB. 2015. Petunjuk Teknis Fasilitasi Ketangguhan Masyarakat Tahun 2015.

BPS Kabupaten Buleleng. 2012. Potensi Desa Kabupaten Buleleng Tahun 2011.

Departemen Dalam Negeri RI.2007. Penanggulangan Bencana. UU No. 24 Tahun 2007.

Munir, Miftakhul. 2017. Evaluasi Pelaksanaan Program Desa Tangguh Bencana di kabupaten Kendal Tahun 2016. Skripsi. Universitas Diponogoro.

Nora, Nurtiana. 2017. Partisipasi Masyarakat Dalam Program Desa Tanguh Bencana di Desa Teluk Bakau Kabupaten Bintan. Skripsi. Universitas Maritim Raja Ali Haji.

Putra, I Wayan Krisna Eka dan Sutarjo. 2017. IbM Pelatihan Pembuatan Peta Risiko Bencana Bagi Staff Badan Penanggulangan Bencana Daerah (BPBD) Kabupaten Buleleng Sebagai Landasan Desa Gitgit Tangguh Bencana Tahun 2017. Laporan Pengabdian. Universitas Pendidikan Ganesha. 